\title{
The Relationship between Climate Change Concern and National Wealth
}

\author{
Alex Y Lo \\ The University of Hong Kong
}

Alex T Chow

Clemson University

\begin{abstract}
Based on a cross-national social survey, this paper ascertains how perception of climate change is related to national wealth and adaptive capacity across 33 countries. Results indicate that citizens of wealthier countries tend to see climate change as the most important problem, but are less likely to rank it as a highly dangerous threat. We find that Gross Domestic Product (GDP) per capita correlates positively with perceived importance of climate change, but negatively with perceived risk. Also, climate change is less likely to be seen as highly dangerous in those countries that are better prepared for climate change. These findings have important implications for climate adaptation. The relatively weaker sense of danger among the wealthiest societies may eventually lead to maladaptation to climate change. Adequate economic resources provide people collective security and protection from impending crises, but could elevate a self-assuring attitude that might prematurely reduce their caution toward the impending threat and capacity for dealing with climate uncertainties.
\end{abstract}

Keywords: climate change concern, risk perception, GDP, climate adaptation, environmental attitude, International Social Survey Programme

Citation:

Lo, A.Y. and Chow, A.T. (in press) The Relationship between Climate Change Concern and National Wealth. Climatic Change. DOI: http://dx.doi.org/10.1007/s10584-015-1378-2

Publisher version available from the authors: alexloyh@hku.hk 


\section{Introduction}

It is often assumed that wealthier individuals and societies are more concerned about the environment than do the poorer ones (Adeola, 1998; Franzen and Vogl, 2013). However, this assumption comes at odds with the observation that climate change skepticism has risen to prominence in the wealthiest societies (Climate Institute, 2012; Lo, 2014; McCright et al., 2013). A number of national and international surveys have suggested that citizens of these societies do not necessarily indicate greater concern about global climate change (Leiserowitz, 2005; McCright and Dunlap, 2011). The present paper provides a qualified support to this view by exploring the relationship between national wealth and climate change concern.

Studies show that there is a non-linear, or even negative relationship between wealth and climate change concern (Kim and Wolinsky-Nahmias, 2014; Sandvik, 2008). Some authors have suggested that success in wealth accumulation is precisely a key factor contributing to the lesser concern, and this appears to be more evident in the wealthiest countries, such as Norway and the U.S. (Leiserowitz, 2005; Norgaard, 2011). As Hulme (2009) and Norgaard (2011) argue, knowledge of the historical and causal linkage between wealth accumulation and anthropogenic climate change could undermine the established belief in national success.

This counter-intuitive argument has found evidence from Sandvik's (2008) study. His cross-national study shows that GDP, as a proxy for national wealth, is negatively related to the proportion of a population considering global warming as a serious problem. The amount of national $\mathrm{CO}_{2}$ emissions per capita also has negative, albeit marginal, impacts on concern over global warming. Yet, Sandvik’s (2008) study is found to have a terminological limitation that has

shadowed a more balanced and intuitively challenging view about the effects of national wealth. 
The study defines public concern as perceived seriousness of a problem, which is a key component of perceived risk. Climate change concern, however, is not necessarily congruent with perception of climate change risk.

‘Concern' has conceptually distinctive dimensions. For example, Dunlap and York (2008, p. 533) define environmental concern as 'concern about environmental problems and support for environmental protection". Likewise, Franzen and Vogl (2013, p. 1002) describe it as "an individual's insight that humans endanger the natural environment combined with the willingness to protect nature”. These definitions consist of two components: 1) the cognitive component of developing the insight about the endangered environment, and 2) the conative component of being willing to perform an action (Franzen and Vogl, 2013). The conceptual distinction lends support to the use of separate measures in the study of climate change concern. Climate change concern can be understood as an expression of risk and priority for action. In Whitmarsh's (2008, p. 362-363) study, for example, 'perceived threat of climate change' and 'perceived importance of climate change' are treated as two different items - the former referring to 'perceived risk' whereas the latter 'issue importance' - and they do not vary with socio-economic and attitudinal variables in the same way. This approach separates the cognitive component (assessing the likelihood or magnitude of potential impacts) from the evaluative one (ranking by the significance of issue).

The present research accounts for the analytic distinction between two attributes of climate change concern, i.e. issue importance and risk perception. Following Sandvik (2008), we hypothesize a negative relationship between national wealth and perceived risk of climate change, but draw on a different, more recent international dataset in an attempt to update and advance the argument that both dimensions of climate change concern are a function of national wealth. Our 
research contributes to the literature by showing that the two attributes of concern are related to national wealth in different ways, i.e. positively and negatively respectively. The remainder of this paper begins with a brief conceptual introduction to the key components of environmental concern, followed by a description of research methods and discussion of results.

\section{National wealth and environmental concern}

According to Ronald Inglehart (1990), national wealth accounts for the growing environmental concern in wealthy societies. Inglehart argues that there has been a gradual shift in people's values towards post-materialism as societies develop and accumulate a certain level of wealth, making advanced industrial societies more environmentally conscious and active than developing societies.

In a recent cross-national study, Franzen and Vogl (2013) find that wealthier countries indeed show higher levels of public support for environmental protection. They propose a 'prosperity' hypothesis (Franzen and Meyer, 2010, p. 221), which postulates a positive relationship between a country's wealth and the level of environmental concern of its citizens. This hypothesis supports Inglehart's (1990) theory, which suggests a positive wealth effect. Supporting evidence on climate change concern specifically has been reported in recent empirical studies (Brulle et al., 2012; Kvaløy et al., 2012).

However, counter-evidence has been reported and the post-materialist hypothesis has come under attack (Dunlap and York, 2008; Kim and Wolinsky-Nahmias, 2014; Marquart-Pyatt, 2008). These cross-national studies show that lower income countries indicate greater concern

about environmental degradation (Dunlap and York, 2008; Gelissen, 2007). The observed 
negative effects contradict the post-materialist assumptions, and imply that environmental activism and public support for environmental protection are not limited to wealthier societies and have become a global phenomenon (Adeola, 1998; Dunlap and York, 2008).

Evidence on this alternative theory is far from conclusive. Dunlap himself has found contrasting observations in two different cross-national surveys, i.e. in one survey, citizens of lower income countries are more likely than those in affluent societies to see environmental problems as a serious threat (Dunlap and Mertig, 1995), but the other one does not offer support to this claim (Dunlap and York, 2008, p. 541). Adeola (1998, p. 350) finds clues for the globalization hypothesis, but suggests that citizens of richer nations are more willing to financially contribute to environmental protection. Gelissen (2007, p. 411) has also reported conflicting evidence.

Furthermore, the findings of these authors are based on different sources of data or survey waves and the countries included in these surveys are not identical. For example, higher-income countries are over-represented in the International Social Survey Programme (ISSP) 2010 Environment Module, whereas lower-income ones are the majority in the World Values Survey (WVS). Results might depend on which combination of countries is included in analysis, but few attempts have been made to distinguish between concepts and samples. There is a lack of consensus among researchers as to how national wealth contributes to cross-national variations in environmental concern.

In an attempt to bring further clarity to this debate, we argue that climate change concern should be understood as a function of at least two different attributes, which previous studies have tended to implicitly or explicitly conflate. We make a distinction between perception of issue importance, which requires judgment on the priority of an issue, and perception of danger, 
which connotes a sense of insecurity and involves an assessment of the intensity of a potential threat and probability of the risk.

Several national studies lend support to this discriminative treatment. Leiserowitz (2005, p. 1440), for example, concludes that most Americans demonstrate 'significant concern' about the issue of global climate change, but 'the majority of the American public does not currently consider climate change an imminent or high-priority danger'. Norgaard (2011) notes that in Norway, global warming was both common knowledge and unimaginable among highly educated individuals. Citizens of these highly developed economies are aware of climate change, but do not appear to worry about its potential catastrophic consequences. In contrast, although citizens of less developed countries put climate change at a lower priority than other social objectives, they are more likely to feel insecure and describe it as a very serious threat to them. This means that, counter-intuitively, perception of issue priority does not follow perception of risk. Whitmarsh (2011) arrives at a similar conclusion: although belief in anthropogenic climate change did not change over a five-year period, perception of the severity of climate change declined. We further develop this view and propose that wealth is related to perceptions of issue importance and risk in different ways.

The proposed approach is premised upon the hypothesis that national wealth negatively correlates with risk perception. The negative wealth effect may stem from an informed ignorance of a known threat. Sandvik (2008) and Norgaard (2011) argue that the awareness of national contributions to the problem of climate change produces a sense of internal ambivalence or even 'guilt' among some citizens of wealthier countries. Particularly in fossil-fuel dependent countries, people are highly sensitive to the economic impacts of mitigating climate change by reducing the use of fossil fuels (Bang, 2010), despite their being generally informed of the causes and 
consequences of climate change. The conflict in beliefs eventually leads to misinterpretation or rejection of those information or beliefs that contradict their existing values. At the society level, this contributes to the tendency among richer communities for downplaying the reality or enormity of climate change to avoid the troubling emotional and psychological entanglement and identity conflicts that arise from the knowledge that they presently as well as historically contribute to the 'wrong thing' (Norgaard, 2011), i.e. producing excessive amount of greenhouse gases. Awareness of one's own responsibility for the problem may result in lower perception of risk.

However, these explanations cannot fully explain the positive relationship between climate change concern and national wealth found elsewhere. If wealth accumulation contributes to low perception of danger, it should also result in reluctance to express concern. The expected coherence is not found in the following analysis. The observation that wealthier societies downplay the risk of climate change requires further explanation.

Perceptions of issue importance and risk should be treated as two different concepts. We propose that they are affected by variation in wealth differently. That is, risk perception is negatively related to national wealth, whereas perception of issue importance responds to wealth in a positive way. In addition, we propose that the capacity for adapting to climate change may be a reason for the lower perception of danger among wealthier countries, which generally have greater adaptive capacity and their citizens may therefore feel protected and tend to be less concerned about the consequences of climate change. The following sections examine these claims. 


\section{Materials and Methods}

This research is based on secondary data obtained from an international research program and other public databases and publications. This section provides details about data sources and describes the statistical variables used in our analysis.

\subsection{Dependent Variables}

The dependent variables include two items representing issue importance and risk perception. They were extracted or computed from the openly available dataset managed by the ISSP Research Group (2012). The Environment Module of the ISSP maintains a collection of national surveys conducted in 2010/11 using nearly the same questionnaire and methodology. These surveys gauged the environmental attitudes, perceptions and behaviors of citizens of 34 countries worldwide (see figures below for list of countries) ${ }^{1}$. National sample sizes range from 928 to 3112 individuals, with a median of 1260 , altogether yielding more than 48,000 observations. The data were collected using stratified random sampling methods to achieve demographic representativeness.

Two of the variables included in the ISSP aggregate data file were enlisted to address the analytical issues raised in previous sections. National average scores were computed for each variable and used as the primary unit for subsequent analysis. The first item is 'Issue Importance', which is a measure of perceived importance of climate change to the respondents' country of residence. The cross-national surveys included a list of nine contemporary environmental problems and respondents were asked to nominate the most important one to their own country

\footnotetext{
${ }^{1}$ The Australian and Dutch data files were not downloadable from the ISSP's public website but available from the program administrator upon request. Taiwan was excluded from our analysis, because it is not represented in the ND-GAIN Index and the World Bank's database so that there is no energy use estimate for the country.
} 
(exclusive choice). Those respondents who nominated climate change were coded as ' 1 ', otherwise ' 0 '. Issue Importance represents the proportion of respondents who gave priority to climate change and is a relative rather than an absolute measure - relative to other environmental problems. This importance question entails judgment on the priority of an issue and can be distinguished from the risk perception variable that involves an assessment of the intensity of a potential threat.

The second dependent variable is 'Risk Perception', which denotes the belief that the rising temperatures as a result of climate change are dangerous. It was measured using a five-point scale, ranging from 'Not dangerous at all (1)' to 'Extremely dangerous' (5) (observations were reverse coded in our aggregate dataset). Perceived danger implies and integrates both perceived likelihood and severity dimensions, which are the two core elements of perceived risk. National average scores of this measure are used in this research to represent perception of climate change risk at a country level.

Our main analysis is based on the ISSP surveys. The use of this single dataset is methodologically limited because the least developed countries are under-represented in the ISSP Environment Module. To address this limitation we employ another popular cross-national dataset, i.e. the WVS ${ }^{2}$. The fourth wave of WVS was conducted between 2005 and 2007 in 47 countries, including a number of lower-middle income countries and least developed countries. The WVS surveys included a single question on climate risk perception: Is global warming or the greenhouse effect serious? Options ranged from 'not serious at all' (1) and 'very serious’ (4) (observations were reverse coded). Response to this question represents perceived seriousness of climate change. It was used for this study because it elicited perception of the threat of global

${ }^{2}$ Available from http://www.worldvaluessurvey.org. 
warming in a way similar to Sandvik's (2008) study and the ISSP questionnaire. While 'seriousness' and 'danger' may have nuanced connotations, they are seen as a cognitive component of concern in this paper.

\subsection{Independent Variables}

This research employed population-adjusted measures of GDP and $\mathrm{CO}_{2}$ emissions as generic indicators of national wealth and present responsibility for climate change, respectively. Per capita GDP data were extracted from the World Bank’s DataBank program. We selected the 2010 GDP statistics ${ }^{3}$ (constant 2005 prices in USD), because most of the ISSP national surveys were conducted in 2010. For the same reason, we retrieved the 2010 national emissions data from the International Energy Agency's (2013) summary tables, which are available in the form of tonnes of $\mathrm{CO}_{2}$ emissions per capita.

We also included energy use estimates as an independent variable. Intuitively it is hard to draw a link between personal $\mathrm{CO}_{2}$ emissions, as a proxy for present responsibility, and the low concern about climate change. Most people do not have or never seek information on the total amount of $\mathrm{CO}_{2}$ emissions they produce from their everyday activities. A conceptually more robust alternative to $\mathrm{CO}_{2}$ emissions is energy consumption, which is a relatively more conscious and visible activity. We employed official estimates on the amount of energy use to approximate present responsibility for human-induced climate change. We solicited the 2010 estimates of oil consumption (kg of oil equivalent per capita) from the International Energy Agency.

The fourth independent variable is the Notre Dame Global Adaptation Index (ND-GAIN) managed by the University of Notre Dame in the United States (http://gain.org). The ND-GAIN

\footnotetext{
${ }^{3}$ At the time of research, the World Bank database was not able to provide the GDP records for Argentina. The GDP estimate used in this study was solicited from the International Energy Agency (IEA, 2012).
} 
Index shows which countries are best prepared to deal with global changes, notably climate change. It serves as an overall measure of a country's vulnerability to climate-related hazards and its readiness to adapt to the challenges posed by climate change and other global forces. The Index is calculated as the readiness score of a country minus its vulnerability score, on a scale from 0 and 100 (the higher the better). The readiness score is a function of the ability of a country's private and public sectors to absorb financial resources and mobilize them efficiently to reduce climate change vulnerability, whereas the vulnerability score is a measure of the degree to which a system is susceptible to, and unable to cope with, adverse effects of climate change. The ND-GAIN Index is used in this study as an indicator of preparedness for global climate change.

\subsection{Data Analysis}

Each of the two dependent variables (Issue Importance and Risk Perception) was regressed against the four independent variables (GDP, Energy Use, $\mathrm{CO}_{2}$ and ND-GAIN Index). We selected regression models based on the Akaike Information Criterion corrected (AICc) for small sample size. AICc scores are often shown as $\triangle \mathrm{AIC}$ scores, or difference between the best model and each model. The best model has the smallest AIC and a $\triangle \mathrm{AIC}$ of zero.

\section{Results}

4.1 Correlations and regression models

Bivariate correlation coefficients for all variables are presented in Table 1 . There is no significant relationship between Issue Importance and Risk Perception, suggesting that they are 
statistically independent of each other ${ }^{4}$. The two dependent variables respond to the listed national-level factors in opposite ways. Issue importance increases with GDP, energy use and ND-GAIN Index, but not CO2, whereas perceived danger of climate change is negatively associated with all of these variables.

Table 2 indicates that the best model for Issue Importance $\left(\mathrm{R}^{2}=0.35, \mathrm{~N}=33\right)$ includes GDP per capita only $(\mathrm{t}=0.609$, S.E. $=0.000)$. Risk Perception, as shown in Table 3 , is best explained by a two-item model $\left(\mathrm{R}^{2}=0.44, \mathrm{~N}=33\right)$ including energy use $(\mathrm{t}=-2.515$, S.E. $=$ 0.000) and ND-GAIN Index $(t=-2.341 \text {, S.E. }=0.007)^{5}$. The following analysis therefore focuses on these three independent variables, whereas $\mathrm{CO}_{2}$ per capita is omitted because of limited statistical significance.

\subsection{Perceived importance of climate change}

Figure 1 shows that GDP per capita varies with Issue Importance in the same direction. Citizens of Japan indicated an exceptionally high level of concern. The national average of .49 suggests that nearly half of the Japanese respondents nominated climate change as the most important environmental problem to the country (the correlation coefficient increases from .609 to .723 when Japan is excluded). Other high-ranking countries include Norway, Germany, and Austria. Developing and transition economies, such as Israel, Lithuania, and Chile, are at the bottom of

\footnotetext{
4 The lack of statistical significance was found only between countries (i.e. national scores) but not within countries (i.e. personal scores), probably due to the ways that these scores were coded. A personal score of ' 0 ' ignores the fact that climate change may still be regarded as a second important issue. National scores are expressed in the form of percentage of respondents and represent the general tendency within the entire country, and this procedure can more or less mitigate the 'all or nothing' bias in personal scores.

${ }^{5}$ Cook's distances permit exclusion of three statistically influential outliners, but this does not significantly affect the selection of optimal models and the correlations between variables. See Appendix for details.
} 
the list.

Energy use does not have strong impacts on Issue Importance (see Table 1). The ND-GAIN Index is a function of GDP per capita. Similar to GDP, the Index runs in the same direction as Issue Importance. This means that climate-resilient countries, such as Switzerland, Denmark and Norway, are more likely to see climate change as the highest priority environmental issue. However, neither energy use nor the ND-GAIN Index contributes to the optimal regression model (see Table 2)

\subsection{Perceived danger of climate change}

The belief that anthropogenic global warming is a very dangerous event declines as GDP increases (see Table 1). Norwegians have the highest incomes among the 33 countries but are the second most likely to downplay the threat of climate change. The lowest and the third lowest average values were recorded in Australia and the Netherlands, both having a high proportion of population in danger of flooding and inundation. Although national wealth is negatively correlated with risk perception, its statistical impacts diminish when the ND-GAIN Index is introduced to the regression analysis (see Table 3).

Energy use is a significant predictor of risk perception. The downward sloping curve displayed in Figure 2 suggests a negative relationship. High energy users include Australia, Belgium, Canada, Finland, and Norway and the U.S. With the exception of Canada, they score lower on the risk perception measure than the rest of the sample, but still around the level of 3.0-3.5, suggesting that they consider climate change as 'somewhat dangerous'. On the other hand, most of low energy users $(<2,000 \mathrm{~kg}$ oil equivalent per capita) are developing or transition economies, such as Philippines, Turkey, Mexico, Chile, Argentina, and Croatia, and they tend to 
see climate change as ‘very dangerous’ (4.0-4.4).

Climate-resilient countries, such as Switzerland, Denmark and Norway, are less concerned about the danger of climate change than the less resilient ones, such as the Philippines. Figure 3 illustrates a negative relationship. Climate change preparedness is a strong correlate of GDP per capita and may be seen as a substitute for the latter. GDP per capita is itself a strong predictor for Risk Perception, but the explanatory power diminishes when climate change preparedness is controlled for.

\subsection{Differential impacts of national wealth}

In the ISSP dataset the negative correlations between national income and risk perception are found among richer countries only. We divided the sample into two groups by convenience, i.e. countries with GDP per capita greater than US\$20,000 and those below US\$20,000. Significant relationships between GDP per capita and risk perception are evident within the former group (r $=-460, \mathrm{p}<.05, \mathrm{~N}=19)$, but not the latter one $(\mathrm{r}=-269, \mathrm{p}>.05, \mathrm{~N}=14)$. The significant impacts of ND-GAIN Index on risk perception are also limited to the richer countries $(r=-593, p<.01$, $\mathrm{N}=19)$, but not the poorer ones $(\mathrm{r}=-337, \mathrm{p}>.05, \mathrm{~N}=14)$.

Similarly, the WVS dataset demonstrates a negative relationship between GDP per capita $(2006)^{6}$ and perceived seriousness of climate change impacts. However, statistical significance is only found in a subset of countries, namely, higher income economies with GDP per capita exceeding US\$20,000 ( $\mathrm{r}=-.565, \mathrm{p}<.05, \mathrm{~N}=13)$. Countries with GDP per capita below US\$20,000 do not demonstrate the negative wealth effect $(r=.274, p>.05, N=34)$, and the same results were found for the full sample $(r=.184, \mathrm{p}>.05, \mathrm{~N}=47)$.

\footnotetext{
${ }^{6}$ Since the WVS surveys were completed between 2005 and 2007, we used the 2006 GDP per capita estimates available from the World Bank's database for this analysis.
} 
National preparedness to climate change ${ }^{7}$ yields similar results, with a higher correlation coefficient than GDP per capita $(\mathrm{r}=-.787, \mathrm{p}<.05, \mathrm{~N}=12)$. The highest ND-GAIN scores (2006) are recorded in Switzerland, Norway and Finland. These countries' higher levels of climate resilience are followed by relatively lower levels of perceived seriousness of climate change. Countries with GDP per capita below US\$20,000 do not indicate the same pattern of variations (r $=.327, \mathrm{p}>.05, \mathrm{~N}=33)$.

The WVS data corroborate the findings that the ND-GAIN Index is a more important factor than GDP per capita, although the former is likely to be an effect of the latter. The best model permits the inclusion of ND-GAIN Index only. The statistical impacts of GDP per capita diminish when climate change preparedness is controlled for. Details are available in Appendix.

\section{Discussion}

National wealth influences perceptions of the importance and the danger of climate change in different ways. Wealthier nations have a higher proportion of educated citizens being informed of and recognizing climate change as an important issue. They might also have achieved greater success in tackling domestic environmental problems, such as air and water pollution, than poorer nations that continue to suffer from these problems. On the other hand, climate change is a global issue that no single country could solve effectively, making it appearing to be a relatively more urgent and pressing problem than the domestic ones for which effective solutions have been identified and implemented in the developed world (the survey question about issue importance involved an exclusive choice from a list of key environmental problems). This could

\footnotetext{
7 Taiwan and Andorra were excluded because they are not represented in the ND-GAIN Index (total N = 45)
} 
explain why perceived importance of climate change increases with national wealth.

However, perception of importance does not carry the same meaning as perception of danger, which emphasizes the sense of insecurity. Risk perception demonstrates a negative association with national wealth. This finding is an improvement in knowledge from Sandvik's (2008) study. Sandvik (2008) concludes that public concern about climate change decreases with national wealth and actual responsibility for the problem. The use of terminology is debatable, because Sandvik (2008) equates concern with perceived seriousness of climate change, whereas perceived issue importance is not taken into consideration. We address this limitation by comparing the two attributes of climate change concern, i.e. perceived importance and risk, and demonstrating the important analytical distinction. National wealth is positively associated with perceived importance of climate change, but negatively with perceived danger or risk. Actual responsibility, defined in terms of energy consumption, and preparedness for climate change vary with the latter in the same way. Perceptions of importance and risk do not necessarily cohere.

Capacity to cope with climate change could explain these contrasting results. According to Bubeck et al (2012), individuals feel protected when they believe that the actions they have taken can effectively mitigate the risks confronting them, such as purchasing flood insurance cover for their home (Bubeck et al., 2012; Lo, 2013a, b). Perceived effectiveness in responding to threats could elevate a sense of protected assurance such that the individuals no longer perceive the risk as high. That is, losing the house becomes a less dreadful issue if full compensation is believed to be guaranteed.

Wealth is undoubtedly a major source of protection from crises by empowering people to mobilize key resources to recover from economic losses and life disruptions incurred by natural 
perils. Richer countries have better infrastructure, technologies, social security systems, emergency supplies, and community supports to help their citizens cope with catastrophic events. Climate change poses threat to all societies, but the wealthiest societies are better equipped and more capable of mitigating risks and coping with its consequences than the rest of the world. Members of these societies recognize the significance of climate change, but also believe that adequate resources are available for coping with catastrophic events and safeguarding potential victims. The wealth of nation is a powerful and reliable source of protection from societal risks, including the potential impacts of climate change. Consequently, climate change is seen by richer countries as an important but not very dangerous challenge. Perceived collective efficacy is a possible reason for the discrepancy between collective concern and risk perception.

The notion of protected assurance is supported by the observation that perceived risk associated with climate change is negatively related to ND-GAIN Index, which is an indicator of a country's climate change preparedness. This means that countries that are less vulnerable to, and more capable of, coping with climate change are less likely to see it as a dangerous issue. The effects of climate change preparedness appear to be stronger than national wealth, as shown in Table 3 that ND-GAIN produced better models than GDP per capita did. A country’s capacity for dealing with climate change, which appears to mediate the role of national wealth, may contribute to declines in collective perception of danger. Societies that are better prepared for climate change are less concerned about the associated risks.

Our findings improve the arguments of Norgaard (2011) and Sandvik (2008). National wealth contributes to the informed ignorance within the wealthier world - aware and informed of the impending crisis of climate change, but not feeling in danger, in comparison to the less resourced societies. The ability to mobilize critical resources results in both greater awareness of 
the problem and lower vulnerability to its impacts (hence a stronger sense of security), which could undermine the belief that climate change poses a serious threat. The negative wealth effects can be understood in terms of collective protection from and preparation for global climate change.

However, results of the WVS offer only partial support to this claim and our core argument has to be qualified accordingly. Perceived seriousness of climate change varies negatively with GDP per capita as well as ND-GAIN Index, but only among countries with GDP per capita exceeding US\$20,000. No such relationship is found among those with GDP below this level. The negative effects of national wealth and climate change preparedness are limited to developed economies.

\section{Conclusions}

Our findings are generally consistent with Sandvik’s (2008) observations but present two important analytical variations. First, GDP has positive rather than negative impacts on perceived importance of climate change. Nonetheless, a negative relationship is observed for risk perception defined as perceived danger of climate change. Second, energy consumption offers a better explanation than the amount of $\mathrm{CO}_{2}$ emissions for the variations in risk perception.

National wealth correlates with perceived importance and danger of climate change in opposite ways. Citizen of richer countries are more likely to see climate change as an important problem, but less likely to rank it as highly dangerous. A possible explanation is that national wealth provides citizens collective security and (perceived) protection from the impending crisis. With more resources to prepare for and recover from catastrophic events, people in highly 
developed societies feel more secure than their less resourced counterparts. More effective protection and preparation for global changes, which is a function of national wealth, contribute to the lower level of concern about the risks associated with climate change. The findings do not indicate low level of climate change concern among these societies, but one of being concerned but feeling safe.

The diminishing sense of danger may eventually lead to maladaptation to climate change. Societies have increasingly recognized the reality of climate change and achieved success in risk mitigation. Adequate economic resources give people confidence in responding to climate change impacts. However, the knowledge of adequate preparation could elevate a collective self-assuring attitude that might prematurely undermine their caution toward the impending threat and consequently reduce motivation to strengthen or maintain capacity for dealing with climate change impacts. Although the diminishing sense of danger is only found among the developed world, the potential for maladaptation exists as middle-income economies develop and people nurture a (false) sense of security against global change. Climate communication in developed and emerging economies should therefore address the tension between the country's accumulating capacity to cope and the declining sense of caution among the wealthier citizens.

\section{Acknowledgement}

The authors thank the editors and the four anonymous reviewers of Climatic Change for their useful comments and suggestions. The generosity of the International Social Survey Programme for making the useful data openly available is highly appreciated. 


\section{References:}

Adeola FO (1998) Cross-national environmentalism differentials: Empirical evidence from core and noncore nations. Society \& Natural Resources 11:339-364.

Bang G (2010) Energy security and climate change concerns: Triggers for energy policy change in the United States? Energy Policy 38:1645-1653.

Brulle R, Carmichael J, Jenkins JC (2012) Shifting public opinion on climate change: an empirical assessment of factors influencing concern over climate change in the U.S., 2002-2010. Climatic Change 114:169-188.

Bubeck P, Botzen WJW, Aerts JCJH (2012) A Review of Risk Perceptions and Other Factors that Influence Flood Mitigation Behavior. Risk Analysis 32:1481-1495.

Climate Institute (2012) Climate of the Nation 2012: Australian Attitudes on Climate Change. The Climate Institute, Sydney.

Dunlap RE, Mertig AG (1995) Global Concern for the Environment: Is Affluence a Prerequisite? Journal of Social Issues 51:121-137.

Dunlap RE, York R (2008) The globalization of environmental concern and the limits of the postmaterialist values explanation: Evidence from four multinational surveys. Sociological Quarterly 49:529-563.

Franzen A, Meyer R (2010) Environmental Attitudes in Cross-National Perspective: A Multilevel Analysis of the ISSP 1993 and 2000. European Sociological Review 26:219-234.

Franzen A, Vogl D (2013) Two decades of measuring environmental attitudes: A comparative analysis of 33 countries. Global Environmental Change 23:1001-1008.

Gelissen J (2007) Explaining Popular Support for Environmental Protection: A Multilevel Analysis of 50 Nations. Environment and Behavior 39:392-415.

Hulme M (2009) Why We Disagree About Climate Change. Cambridge University Press, Cambridge.

Inglehart R (1990) Culture Shift in Advanced Industrial Society. Princeton University Press, Princeton, NJ.

International Energy Agency (2013) CO2 Emissions from Fuel Combustion - 2013 Highlights. International Energy Agency, Paris.

ISSP Research Group (2012) Environment III - ISSP 2010 (ZA5500 Data file Version 2.0.0, doi:10.4232/1.11418). in GESIS Data Archive (ed.), Cologne.

Kim SY, Wolinsky-Nahmias Y (2014) Cross-National Public Opinion on Climate Change: The Effects of Affluence and Vulnerability. Global Environmental Politics 14:79-106.

Kvaløy B, Finseraas H, Listhaug O (2012) The publics' concern for global warming: A cross-national study of 47 countries. Journal of Peace Research 49:11-22.

Leiserowitz AA (2005) American Risk Perceptions: Is Climate Change Dangerous? Risk Analysis 25:1433-1442.

Lo AY (2013a) Household preference and financial commitment to flood insurance in South East Queensland. Australian Economic Review 46:160-175.

Lo AY (2013b) The likelihood of having flood insurance increases with social expectations. Area 45:70-76.

Lo AY (2014) The right to doubt: climate-change scepticism and asserted rights to private property. Environmental Politics 23:549-569.

Marquart-Pyatt ST (2008) Are There Similar Sources of Environmental Concern? Comparing Industrialized Countries. Social Science Quarterly 89:1312-1335.

McCright A, Dunlap R, Xiao C (2013) Perceived scientific agreement and support for government action on climate change in the USA. Climatic Change 119:511-518.

McCright AM, Dunlap RE (2011) Cool dudes: The denial of climate change among conservative white males in the United States. Global Environmental Change 21:1163-1172. 
Norgaard KM (2011) Living in Denial: Climate Change, Emotions, and Everyday Life. MIT Press Cambridge, Mass.

Sandvik H (2008) Public concern over global warming correlates negatively with national wealth. Climatic Change 90:333-341.

Whitmarsh L (2008) Are flood victims more concerned about climate change than other people? The role of direct experience in risk perception and behavioural response. Journal of Risk Research 11:351-374.

Whitmarsh L (2011) Scepticism and uncertainty about climate change: Dimensions, determinants and change over time. Global Environmental Change 21:690-700. 
Figure 1 Bivariate correlation plot for perceived importance of climate change and GDP per capita ( $\mathrm{N}=$ 33)

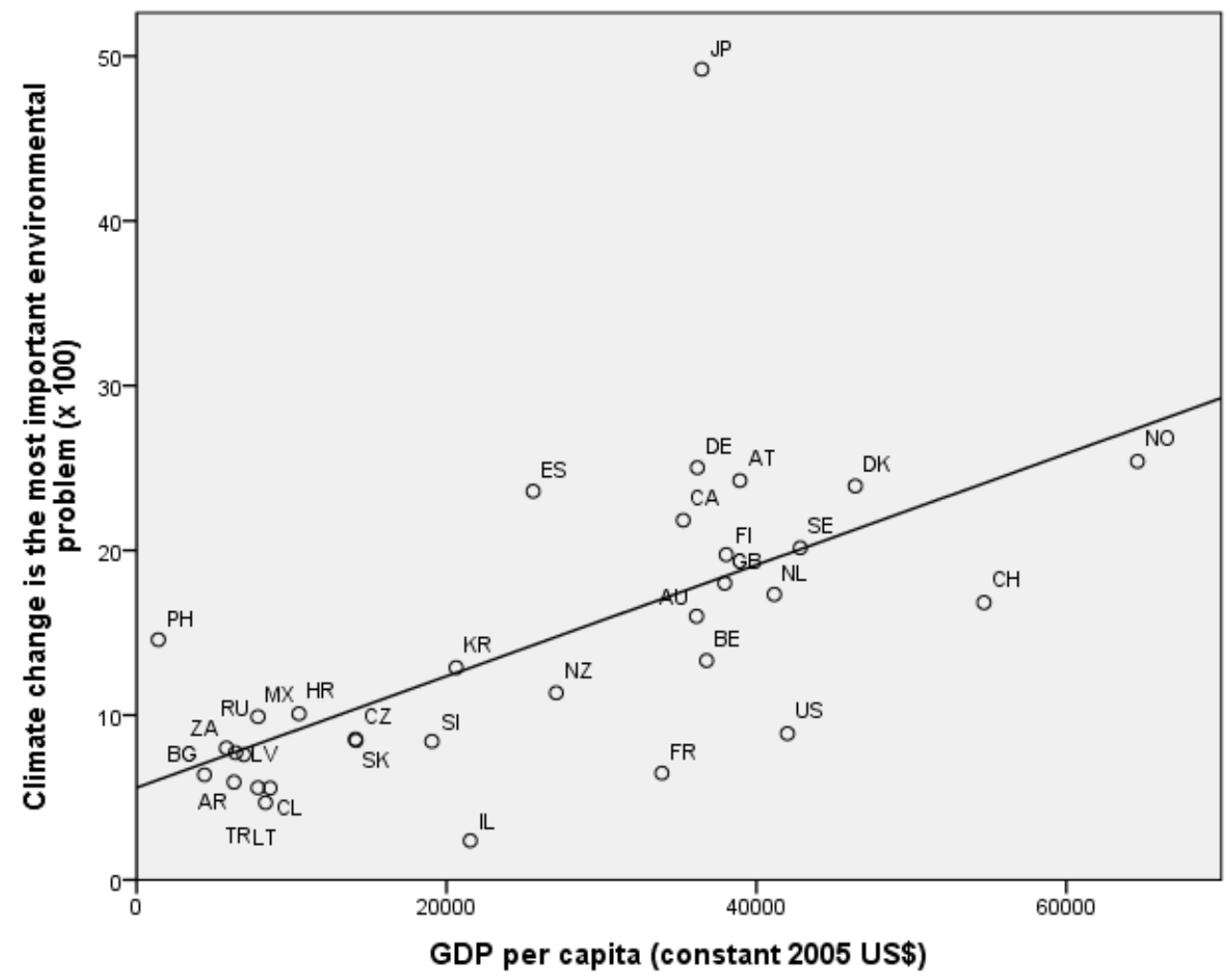

Country code: AR (Argentina), AT (Austria), AU (Australia), BE (Belgium), BG (Bulgaria), CA (Canada), CH (Switzerland), CL (Chile), CZ (Czech Republic), DE (Germany), DK (Denmark), ES (Spain), FI (Finland), FR (France), GB (United Kingdom), HR (Croatia), IL (Israel), JP (Japan), KR (South Korea), LT (Lithuania), LV (Latvia), MX (Mexico), NL (Netherlands), NO (Norway), NZ (New Zealand), PH (Philippines), RU (Russia), SE (Sweden), SK (Slovak Republic), SL (Slovenia), TR (Turkey), US (United States), ZA (South Africa). Based on Cook's distance, Japan is identified as an outliner in the optimal regression model. Exclusion of Japan increases the r value from .609 to .723. 
Figure 2 Bivariate correlation plot for perceived danger of climate change and energy use ( $\mathrm{N}=33$ )

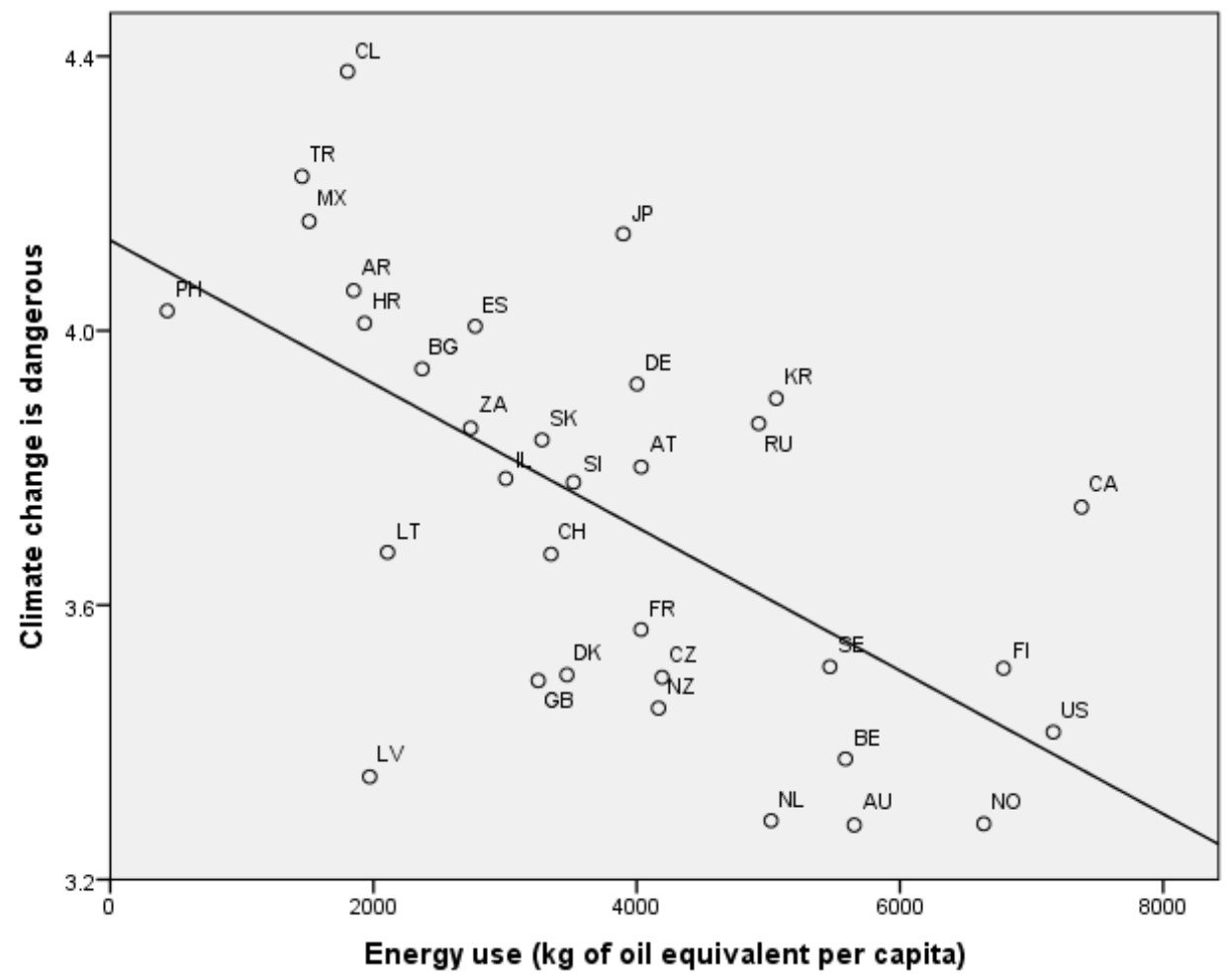

Country code: AR (Argentina), AT (Austria), AU (Australia), BE (Belgium), BG (Bulgaria), CA (Canada), CH (Switzerland), CL (Chile), CZ (Czech Republic), DE (Germany), DK (Denmark), ES (Spain), FI (Finland), FR (France), GB (United Kingdom), HR (Croatia), IL (Israel), JP (Japan), KR (South Korea), LT (Lithuania), LV (Latvia), MX (Mexico), NL (Netherlands), NO (Norway), NZ (New Zealand), PH (Philippines), RU (Russia), SE (Sweden), SK (Slovak Republic), SL (Slovenia), TR (Turkey), US (United States), ZA (South Africa). Based on Cook’s distances, Canada and Chile are identified as outliners in the optimal regression model. Exclusion of Canada and Chile increases the r value from -.617 to -.656. 
Figure 3 Bivariate correlation plot for perceived danger of climate change and ND-GAIN Index ( $N$ = 33)

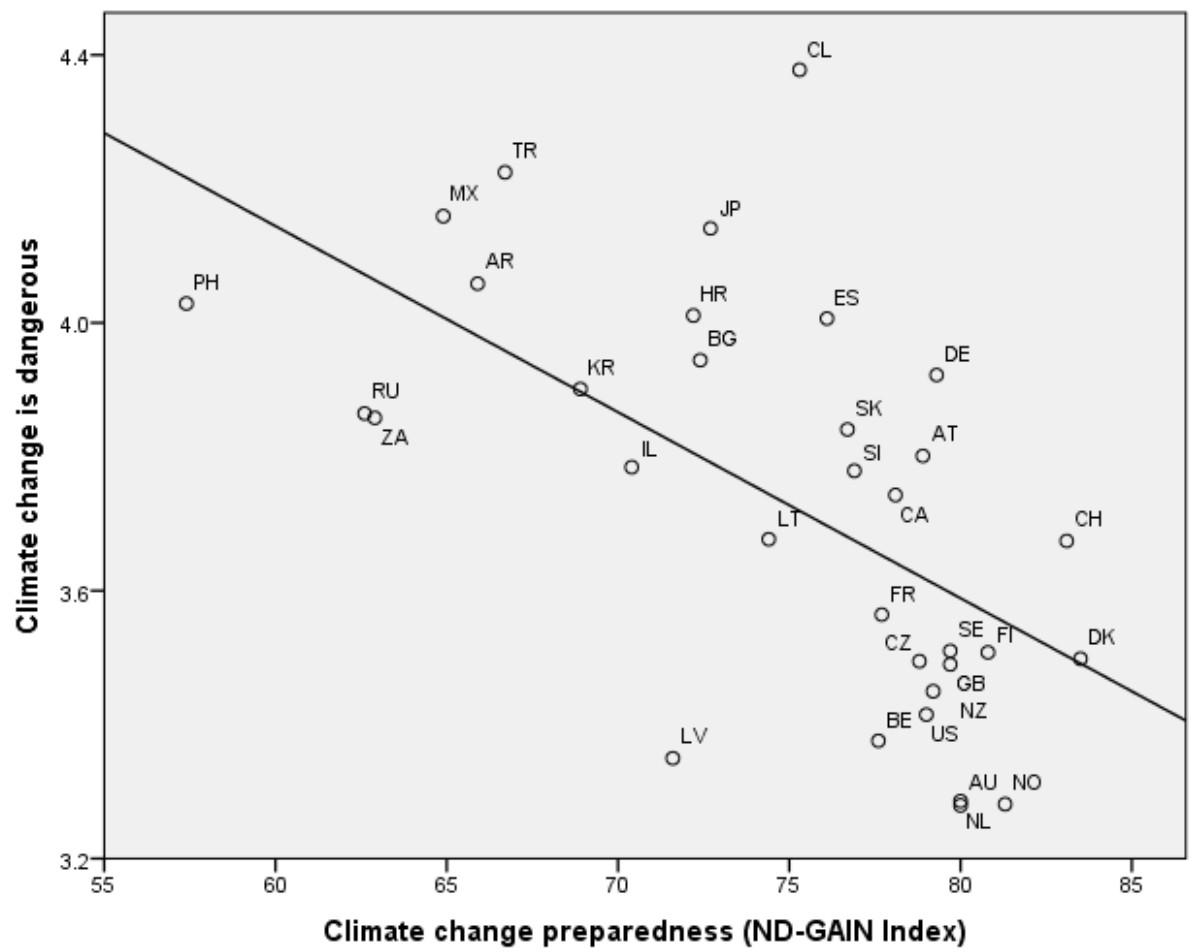

Country code: AR (Argentina), AT (Austria), AU (Australia), BE (Belgium), BG (Bulgaria), CA (Canada), CH (Switzerland), CL (Chile), CZ (Czech Republic), DE (Germany), DK (Denmark), ES (Spain), FI (Finland), FR (France), GB (United Kingdom), HR (Croatia), IL (Israel), JP (Japan), KR (South Korea), LT (Lithuania), LV (Latvia), MX (Mexico), NL (Netherlands), NO (Norway), NZ (New Zealand), PH (Philippines), RU (Russia), SE (Sweden), SK (Slovak Republic), SL (Slovenia), TR (Turkey), US (United States), ZA (South Africa). Based on Cook’s distances, Canada and Chile are identified as outliners in the optimal regression model. Exclusion of Canada and Chile strengthens the negative correlation from -.605 to -.667.

Table 1 Correlation coefficients for climate change concern and country-level indicators $(N=33)$

\begin{tabular}{|c|c|c|c|c|}
\hline $\begin{array}{c}\text { Issue } \\
\text { Importance }\end{array}$ & $\begin{array}{c}\text { Risk } \\
\text { Perception }\end{array}$ & $\begin{array}{c}\text { GDP per } \\
\text { capita }\end{array}$ & $\begin{array}{c}\text { Energy use } \\
\text { per capita }\end{array}$ & $\begin{array}{c}\mathrm{CO} 2 \\
\text { emissions per } \\
\text { capita }\end{array}$ \\
\hline
\end{tabular}




\begin{tabular}{|c|c|c|c|c|c|}
\hline Risk Perception & -.060 & & & & \\
\hline GDP per capita & $.609 * *$ & $-.590 * *$ & & & \\
\hline $\begin{array}{l}\text { Energy use per } \\
\text { capita }\end{array}$ & $.380 *$ & $-.618 * *$ & $.750 * *$ & & \\
\hline $\begin{array}{l}\text { CO2 emissions } \\
\text { per capita }\end{array}$ & .223 & $-.476^{* *}$ & $.459 * *$ & $.719 * *$ & \\
\hline ND-GAIN Index & $.347^{*}$ & $-.605 * *$ & $.787^{* *}$ & $.688^{* *}$ & $.404^{*}$ \\
\hline
\end{tabular}


Table 2 Perceived importance of climate change and national indicators $(\mathrm{N}=33)$

\begin{tabular}{cccccr}
$\begin{array}{c}\text { GDP } \\
\text { (2005 prices } \\
\text { USD per capita) }\end{array}$ & $\begin{array}{c}\text { Energy use } \\
\text { (oil equivalent } \\
\text { kg per capita) }\end{array}$ & $\begin{array}{c}\text { CO }_{2} \text { emission } \\
\text { (tonnes per } \\
\text { capita) }\end{array}$ & $\begin{array}{c}\text { Climate change } \\
\text { preparedness } \\
\text { (ND-GAIN Index) }\end{array}$ & AICc & AAICC \\
\hline$* *$ & - & - & - & 231.403 & 0 \\
$* *$ & - & - & n.s. & 231.462 & 0.059 \\
$* *$ & n.s. & - & - & 233.310 & 1.907 \\
$* *$ & n.s. & - & n.s. & 233.630 & 2.227 \\
$* *$ & - & n.s. & - & 233.788 & 2.385 \\
$* *$ & - & n.s. & n.s. & 234.129 & 2.726 \\
- & n.s. & n.s. & - & 235.987 & 4.584 \\
- & - & - & $*$ & 242.494 & 11.091 \\
- & n.s. & - & - & 242.617 & 11.214 \\
- & n.s. & - & n.s. & 243.911 & 12.508 \\
- & - & - & - & 244.296 & 12.893 \\
- & \# & n.s. & - & 244.759 & 13.356 \\
- & - & n.s. & $\#$ & 244.787 & 13.384 \\
- & - & n.s. & - & 245.041 & 13.638 \\
$* *$ & n.s. & n.s. & n.s. & 246.431 & 15.028 \\
& $*$ & n.s. & $\#$ & 247.824 & 16.421 \\
\hline
\end{tabular}

Estimation method: generalized linear models with 'Issue Importance' as dependent variable

$\#, *$ and ${ }^{* *}$ denote significance at $.1, .05$ and .01 levels respectively. n.s.: not significant. 
Table 3 Perceived danger of climate change and national indicators $(\mathrm{N}=33)$

\begin{tabular}{|c|c|c|c|c|c|}
\hline $\begin{array}{c}\text { GDP } \\
\text { (2005 prices } \\
\text { USD per capita) }\end{array}$ & $\begin{array}{l}\text { Energy use } \\
\text { (oil equivalent } \\
\text { kg per capita) }\end{array}$ & $\begin{array}{l}\mathrm{CO}_{2} \text { emission } \\
\text { (tonnes per } \\
\text { capita) }\end{array}$ & $\begin{array}{l}\text { Climate change } \\
\text { preparedness } \\
\text { (ND-GAIN Index) }\end{array}$ & $\mathrm{AlCc}$ & $\triangle \mathrm{AICC}$ \\
\hline- & $* *$ & - & $*$ & 1.287 & 0 \\
\hline n.s. & $*$ & - & \# & 4.043 & 2.756 \\
\hline- & $\#$ & n.s. & $*$ & 4.052 & 2.765 \\
\hline$\#$ & * & - & - & 4.053 & 2.766 \\
\hline- & - & $\#$ & $* *$ & 4.092 & 2.805 \\
\hline- & $* *$ & - & - & 4.224 & 2.937 \\
\hline- & - & $\#$ & $* *$ & 5.000 & 3.713 \\
\hline$* *$ & - & $\#$ & - & 5.728 & 4.441 \\
\hline n.s. & - & - & \# & 5.790 & 4.503 \\
\hline$* *$ & - & - & - & 5.939 & 4.652 \\
\hline n.s. & - & n.s. & \# & 5.972 & 4.685 \\
\hline- & $* *$ & n.s. & - & 6.642 & 5.355 \\
\hline n.s. & n.s. & n.s. & - & 6.846 & 5.559 \\
\hline n.s. & n.s. & n.s. & \# & 7.037 & 5.750 \\
\hline - & - & $* *$ & - & 11.588 & 10.301 \\
\hline- & - & - & - & 17.635 & 16.348 \\
\hline
\end{tabular}

Estimation method: generalized linear models with 'Risk Perception' as dependent variable

\#, ${ }^{*}$ and ${ }^{* *}$ denote significance at $.1, .05$ and .01 levels respectively. n.s.: not significant. 